\title{
Effect of Self Care Guideline on the Quality of Life among Women With menopausal symptoms
}

\author{
Heba ali shabaan *, shadia Hamido Mohasib, **, EkbalAbd-Elraheem Emam ***,
}

1. master degree.2. Professor of maternal 1\& Newborn nursing, faculty of nursing- Ain shams University. 3. Assistant professor of maternity \&child Health nursing faculty of nursing Minia university

*Email of the corresponding author: heba m535@yahoo.com

\section{Abstract}

Background Women spend over one-third of their life in postmenopausal period Regarding this issue, considering the quality of life for women in postmenopausal period, The aim of this study was to evaluate the effect of self care guidelines on the quality of life among women with menopausal symptoms. The quasi-experimental Design(time series design) was conducted in Obstetrics and Gynecology hospital in Elminia city. The purposive sample technique was used to recruit one hundred of menopausal women Tools Interviewing sheet, Menopause specific quality of life questionnaire (MENQOL). Results of the study illustrated that there were a strong association between severity of menopausal symptoms as "vasomotor, somatic, , psychosomatic, urogenital symptoms" and lower level of QOL during the menopausal period. There were a significant differences between Pre and post intervention regarding total mean score of quality of life of the menopausal women The study concluded that guideline is an effective complementary health approach for improving quality of life in menopausal women. Recommendations Self-care guideline should be used in health care centers as a routine care for menopausal women.

Keywords: Quality of life, menopausal woman, self care guideline

\section{Introduction}

Women face specific issues arising from their physiological conditions. One of these issues is menopause transition period that is associated with complications. Some of these effects include vasomotor disturbances, hot flashes, night sweats, and psychological changes of mood disorders, depression, anxiety, loss of concentration, memory loss and irrigation, sexual dysfunction. (1)

Menopause does not really require medical treatment since it is a natural biological process. Treatments for menopause focus on relieving its symptoms and preventing any chronic condition that may occur during the postmenopausal years, such as heart disease and osteoporosis. Exercise, an appropriate diet, not smoking, and reduction of stress are also effective ways to make menopause more bearable and also facilitate in preventing the chronic ailments that may occur in the postmenopausal years.( 2)

Menopause is a stressful time for some women. However, strategies for managing stress can help women cope, not only with menopause, but with life and aging in general. Practices such as relaxation exercises, biofeedback, aerobic exercise, yoga, meditation, and breathing techniques are tools that enable these women to deal with stress in their lives.( 3)

Complications of menopause were heart and blood vessel (cardiovascular) disease, osteoporosis, urinary incontinence, sexual dysfunction, due to vaginal dryness, and weight gain .(4)

Health promoting lifestyle education is one of the most important factors in raising postmenopausal women's awareness and improving their performance to improve their health status. All the researches in the field of menopause have also emphasized education of and care for postmenopausal women to prevent their problems (5).

The Orem's Model of Nursing. This theory originates from the totality paradigm based on human beings

$P$ a g e $\mid 34$ able to adapt to one's environment. It is widely used in nursing literature and has displayed improved quality of care based on results from various randomized controlled trials in the nursing discipline .It is particularly used in rehabilitation and primary care settings, where the patient is encouraged to be as independent as possible. (6)

Operational definition for guide line is a document with the aim of guiding decisions and criteria regarding diagnosis, management, and treatment in specific areas of healthcare. Such documents have been in use for thousands of years during the entire history of medicine.A healthcare provider is obliged to know the medical guidelines of his or her profession, and has to decide whether to follow the recommendations of a guideline for an individual treatment. (7)

Menopause symptoms are closely related to QOL of women during menopausal period and can influence QOL of women physiologically, psychologically, and socially.(8)

According to World Health Organization (WHO), QOL is individual's perception of current life situation, in the cultural background and value systems in which she grew up and the relation of these perceptions with her respective goals, expectations, standards, and priorities.( 9 )

Quality of life is used in healthcare to refer to an individual's emotional, social, and physical well-being, including their ability to function in the ordinary tasks of living .It is a term used most frequently in the context of medicine and healthcare, when the impact the disease may reduce health related quality of life. health related quality of life is defined as the impact of an injury or illness has on the QOL including the perception of his or her injury or illness or it is the "value assigned to the duration of life modified by impairments, considering the individual own sense of wellbeing and not the health care provider's perception. (10).

Nurses have a vital role to play in helping women to cope during and after the menopause, offering individual assessment, education and support. All those involved in 
counseling such women must ensure that they know where to get up-to-date information and where to direct clients who are in need of further information. (11)

\section{Significance:}

Overall, by increasing life expectancy, more than one third of a woman's life is spent in menopause, which cause many physical and psychological changes in women (12).

A study of menopausal women revealed that 80 percent experienced no change in quality of life. Sixty-two percent had positive feeling about menopause. Ten percent of women said they were irritable, fatigued, and had feelings of despair during the menopausal phase of their lives .(13)

The transition through menopause is a life event that can profoundly affect quality of life. More than $80 \%$ of the women reported physical and psychological symptoms that commonly accompany menopause, with varying degrees of severity and life disruption few empirical studies, however, have examined the interrelated nature of symptoms associated with the menopausal transition and early postmenopausal and the effects of those symptom groups on quality of life . (14)

Approximately $55 \%$ of women going through menopause don't do anything at all to treat symptoms. Approximately $75 \%$ of women experience hot flashes and night sweats at some point.(15)

\section{Aim of the study}

was to evaluate the effect of self-care guideline on quality of life among women with menopausal symptoms.

\section{Hypothesis:}

There is the positive effect of self-care guideline on the quality of life among woman with menopausal symptoms.

\section{Subjects and methods}

\section{Research design:}

Quasi-experimental design was used to evaluate the effect of self-care guideline on quality of life among women with menopausal symptoms.

\section{Setting:}

The study was conducted in Obstetrics and Gynecology department at maternity and children's hospital in El Minia city(hospital of obstetric \&gynecology and children, university hospital(out patient clinic)

\section{Subjects:}

Any woman attending the study setting is eligible for inclusion in the study sample if she fulfills the following

\section{Inclusion criteria:}

- Woman age 45-65 years.
- Not using hormonal replacement therapy

- Minimum reading and writing is accepted.

- Free from medical conditions like diabetes, hypertension, cardiac disease and thyroid disorder

- $\quad$ Single or married

\section{Exclusion criteria}

- Previous hysterectomy or mastectomy .

- Woman receiving chemotherapy or radiotherapy.

\section{Sample size and type}

Purposive sample of all women at menopausal stage attending to gynecology clinic. At it least 100 women were recruited in the study

\section{Ethical considerations:}

Each participant woman in the study was informed that her rights would be secured, informed about the nature, process, and expected outcomes of the study, reassured that the study procedures would be harmless, reassured that all data would be confidential and would be used only for the research purposes, and informed about her rights to withdraw at any time throughout the study.

\section{Tool of Data Collection}

1st part - Interviewing sheet: was designed by the researcher and it included data about women's socio demographic data: economic state, occupation \& educational level, menstrual status etc...

2nd part - Menopause specific quality of life questionnaire (MENQOL). It is a self-report measure assessing the presence and severity of menopause symptoms and the degree to which they adversely affect women's life designed by (Hilditch and Lewis,2005). It consists of 29 items divided into four domains: vasomotor (three items), psychosocial (seven items), and physical (16 items) and sexual (three items). The systematic scoring for each of the four.

\section{3th- Diary sheet for every woman.}

\section{Pilot study:}

A pilot study was carried out during three weeks on 10 women with menopausal symptoms. It was done to test study process and to evaluate the applicability and clarity of the tools, assessment of feasibility of fieldwork, identification of a suitable place for interviewing women, and to detect any possible obstacles that might face the researcher, and interfere with data collection. Necessary modifications were done based on the pilot study findings. The sample of women included in the pilot study was not included in the main study sample.

\section{Fieldwork description:}

Data collection for this study was carried out during March 2016 to December 2016, during morning shifts. The researcher attended the outpatient unit from 9:00 am to 2:00 pm, 3 days per week. Oral consent for 
Minia Scientific Nursing Journal (Print) (ISSN 2537-012X) Vol. (3) No. (1) July 2018

participation in the study was obtained from every woman for ethical issues.

The researcher started to collect the data from woman by the pre-test on the first visit for follow up.

The researcher introduced herself to the woman in out- patient unit, and explained the purpose of the study was to obtain her consent for participation. Complete personal data were taken, then the effect of menopausal symptoms on health status (medical history), to assess the knowledge of women about menopausal symptoms.

Then Researcher apply posttest for assess the effect of menopausal symptoms on the quality of life and effect of guideline on women's quality of life as physical, psychological, motor and sexual condition of women.

\section{Limitations of the study:}

Some women refused to cooperate, other women didn't want to speak about sexuality.

\section{Statistical Design:}

The collected data were organized, tabulated and analyzed using statistical package of social science (SPSS) 17.0 programs. The data were presented in numbers and percentages. Mean and standard deviation were calculated for quantitative data. Chi-square (X2) test was used for qualitative data and both (T-Test and correlation coefficient) were used for quantitative data, when $\mathrm{P}$ value was equal or less than .05 it was considered significant value.

\section{Result}

Part 1 :Demographic characteristics and history of the menopausal women.

Table(1): Distribution of the studied women according to their Demographic characteristics. $(\mathrm{n}=100)$

\begin{tabular}{|c|c|c|}
\hline Items & $\mathrm{No}$ & $\%$ \\
\hline \multicolumn{3}{|l|}{ 1-Age } \\
\hline $45-49$ & 27 & 27 \\
\hline $50-54$ & 32 & 32 \\
\hline $55-59$ & 25 & 25 \\
\hline $60-65$ & 16 & 16 \\
\hline Mean \pm SD & \multicolumn{2}{|c|}{$53.6 \pm 5.3$} \\
\hline \multicolumn{3}{|l|}{ 2-Marital status: } \\
\hline Single & 7 & 7 \\
\hline Married & 54 & 54 \\
\hline Divorce & 5 & 5 \\
\hline Widow & 34 & 34 \\
\hline \multicolumn{3}{|l|}{ 3-Occupation: } \\
\hline house Wife & 76 & 76 \\
\hline Work & 17 & 17 \\
\hline Pensioner & 6 & 6 \\
\hline Handicapped & 1 & 1 \\
\hline \multicolumn{3}{|l|}{ 4-Education: } \\
\hline Illiterate & 4 & 4 \\
\hline Read, wright & 68 & 68 \\
\hline Diploma & 20 & 20 \\
\hline Above average & 8 & 8 \\
\hline University & 0 & 0 \\
\hline
\end{tabular}

Table (1) Illustrates that, The study included 100 menopausal women aged 45-65 years with a mean age of $53.6 \pm 5.3$ years. Most women were married (54\%); $4 \%$ illiterate and $68 \%$ were able to read and write ; $76 \%$ housewives.

Table(2): Contentious, Distribution of the studied women according to their Personal habits.

\begin{tabular}{|l|l|l|}
\hline Items & No & $\%$ \\
\hline 1 -Body health & & \\
\hline -Excellent & 10 & 10 \\
\hline -Good & 69 & 69 \\
\hline Poor- & 21 & 21 \\
\hline
\end{tabular}


Minia Scientific Nursing Journal (Print) (ISSN 2537-012X) Vol. (3) No. (1) July 2018

\begin{tabular}{|c|c|c|}
\hline Items & No & $\%$ \\
\hline 2-Follow up the special diet & 88 & 88 \\
\hline -Low fat & 61 & 61 \\
\hline - Low carbohydrate & 15 & 15 \\
\hline -High protein & 8 & 8 \\
\hline -Vegetables & 4 & 4 \\
\hline \multicolumn{3}{|l|}{ 3- Stress or life change } \\
\hline None & 35 & 35 \\
\hline Mild 2 & 60 & 60 \\
\hline Moderate 3 & 4 & 4 \\
\hline Sever $\quad 4$ & 1 & 1 \\
\hline \multicolumn{3}{|l|}{ 4-Dealing with anxiety } \\
\hline -Excellent & 13 & 13 \\
\hline -Good & 63 & 63 \\
\hline Poor- & 24 & 24 \\
\hline \multicolumn{3}{|c|}{ 5-Your opinion in menstrual cessation } \\
\hline$+\mathrm{Ve}$ & 78 & 78 \\
\hline$-\mathrm{Ve}$ & 22 & 22 \\
\hline \multicolumn{3}{|c|}{6 What concerns you about menopaus } \\
\hline -Work/ children & 42 & 42 \\
\hline -None & 58 & 58 \\
\hline \multicolumn{3}{|c|}{ 7-Source of Information about menopause: } \\
\hline -Books & 8 & 8 \\
\hline -Internet & 3 & 3 \\
\hline -Magazine & 3 & 3 \\
\hline -Friends & 22 & 22 \\
\hline$-\mathrm{TV}$ & 64 & 64 \\
\hline
\end{tabular}

Table (2) describes personal habits of menopausal women : It shows that less/or more than two thirds had good body health $(69 \%), 61 \%$ preferred Low fat diet, Also $60 \%$ of them had Stress and $63 \%$ had good dealing with anxiety. It is also clear that slightly less than one quarter $(22 \%)$ of them had negative opinion about menstrual cessation.

Table (3): Effect of menopausal symptoms on total level of quality of life of the studied women in pre test ( $\mathrm{n}=100)$.

\begin{tabular}{|l|l|l|l|l|l|}
\hline Quality of life & None & Mild & Moderate & Sever & X \pm SD \\
\cline { 2 - 6 } & $\%$ & $\%$ & $\%$ & $\%$ & \\
\hline & & & & & \\
\hline 1)- Mobility: & 7.3 & 13.0 & 30.0 & 49.7 & $2.22 \pm 0.9$ \\
\hline 2) Psychological: & 14.6 & 27.4 & 36.9 & 21.1 & $1.65 \pm 0.9$ \\
\hline 3)Physical: & 29.8 & 25.4 & 26.4 & 18.4 & $1.49 \pm 1.0$ \\
\hline 4)Sexual: & 38.0 & 20.7 & 27.7 & 13.6 & $1.17 \pm 1.1$ \\
\hline
\end{tabular}

Table (3) describes the effect of menopausal symptoms on total QOL (Mobility, Psychological, Physical , Sexual conditions) of menopausal women in pre test. It was found that the highest mean score was related to women
Mobility(2.22 \pm 0.9$)$, as compared with the lowest mean score related to women (Psychological 1.65 \pm 0.91 , Physical $1.49 \pm 1.0$, and Sexual $1.49 \pm 1.0$ respectively).

Table (4): Effect of menopausal symptoms on total level of quality of life of the studied women in post test ( $n=100$ ).

\begin{tabular}{|l|l|l|l|l|l|}
\hline Quality of life & None & Mild & Moderate & Sever & $\mathrm{X} \pm \mathrm{SD}$ \\
\cline { 2 - 6 } & $\%$ & $\%$ & $\%$ & $\%$ & \\
\hline & & & & & \\
\hline
\end{tabular}


Minia Scientific Nursing Journal (Print) (ISSN 2537-012X) Vol. (3) No. (1) July 2018

\begin{tabular}{|l|l|l|l|l|l|}
\hline \multirow{2}{*}{ Quality of life } & None & Mild & Moderate & Sever & $\mathrm{X} \pm \mathrm{SD}$ \\
\cline { 2 - 6 } & $\%$ & $\%$ & $\%$ & $\%$ & \\
\hline 1)- Mobility: & 22.3 & 35.0 & 42.0 & 0.7 & $1.6 \pm 0.8$ \\
\hline 2) Psychological: & 40.4 & 41.0 & 17.6 & 1.0 & $0.79 \pm 0.8$ \\
\hline 3)Physical: & 52.6 & 32.3 & 14.8 & 0.3 & $0.63 \pm 0.8$ \\
\hline 4)Sexual: & 55.3 & 30.0 & 12.7 & 2.0 & $0.61 \pm 0.8$ \\
\hline
\end{tabular}

Table (4) describes the effect of menopausal symptoms on total QOL (Mobility, Psychological, Physical, Sexual conditions) of menopausal women in post test. It was found that the mean score was reduced in post test relating to women all QOL ( Mobility, Psychological , Physical , and Sexual respectively).

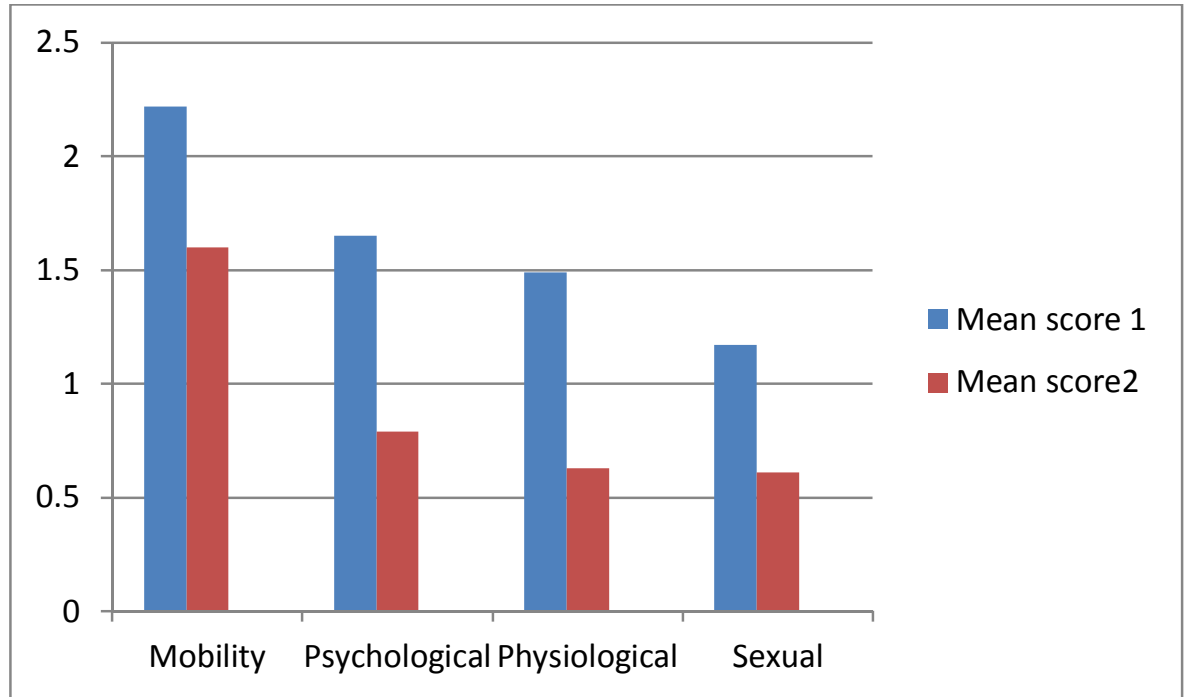

Figure( 1 ): Effect of menopausal symptoms on total mean score of quality of life in Pre and post intervention

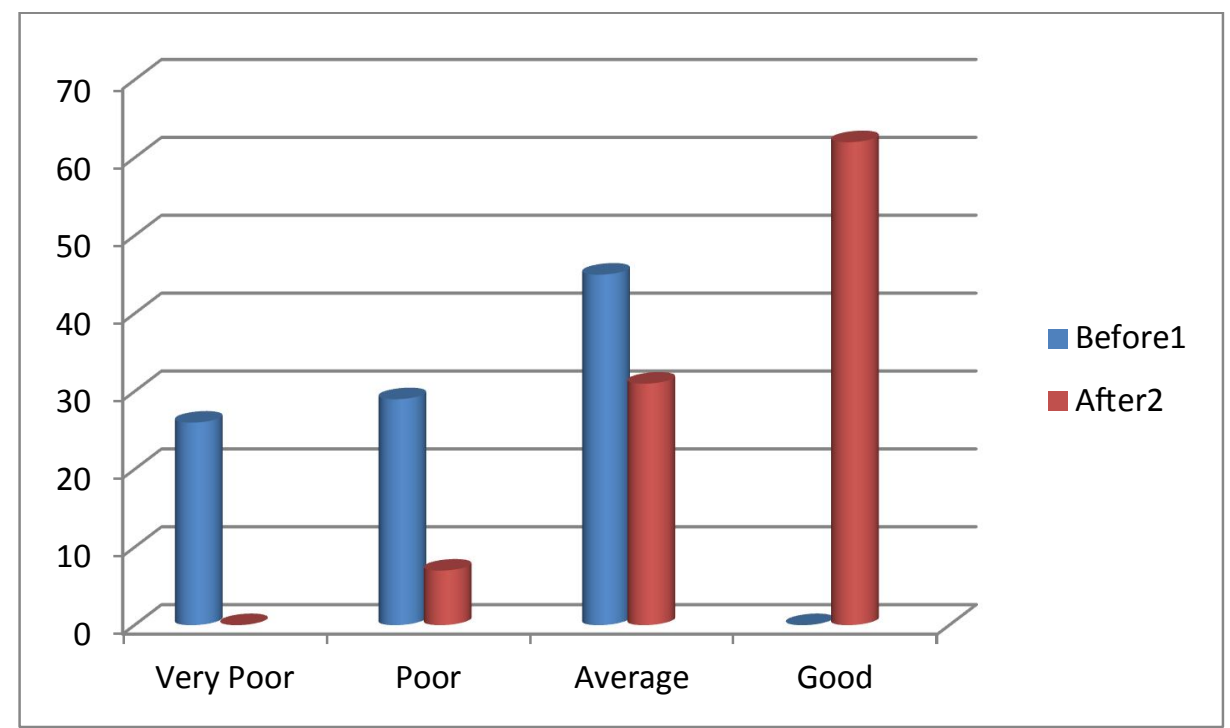

Figure ( 2 ): Total level of quality of life of menopausal women in pre and post Intervention 
Minia Scientific Nursing Journal (Print) (ISSN 2537-012X) Vol. (3) No. (1) July 2018

Table(5): Correlation between the quality of life of the studied women and some demographic variables. $(\mathrm{n}=100)$

\begin{tabular}{|c|c|c|c|c|c|}
\hline \multirow[b]{2}{*}{ some demographic variables } & \multicolumn{3}{|c|}{ Quality of life } & \multirow[b]{2}{*}{$\begin{array}{l}\text { Total } \\
\text { No }\end{array}$} & \multirow[b]{2}{*}{$\mathrm{r}$-Test } \\
\hline & $\begin{array}{l}\text { Average } \\
\mathrm{N}=45\end{array}$ & Poor $\mathrm{N}=29$ & $\begin{array}{l}\text { Very } \\
\text { Poor } \\
\mathrm{N}=26\end{array}$ & & \\
\hline \multicolumn{6}{|l|}{ 1-Age } \\
\hline $45-49$ & 7 & 10 & 10 & 27 & \\
\hline $50-54$ & 14 & 10 & 8 & 32 & -0.310 \\
\hline $55-59$ & 15 & 4 & 6 & 25 & \\
\hline $60-65$ & 9 & 5 & 2 & 16 & \\
\hline \multicolumn{6}{|l|}{ 2-Marital status: } \\
\hline Single & 2 & 3 & 2 & 7 & \multirow[t]{4}{*}{$\mathrm{P}<0.01$} \\
\hline Married & 33 & 9 & 12 & 54 & \\
\hline Divorce & 1 & 2 & 2 & 5 & \\
\hline Widow & 9 & 15 & 10 & 34 & \\
\hline \multicolumn{6}{|l|}{ 3-Occupation: } \\
\hline house Wife & 36 & 21 & 19 & 76 & \\
\hline Work & 8 & 6 & 3 & 17 & 0.329 \\
\hline Pensioner & 1 & 2 & 3 & 6 & $\mathrm{P}<0.01$ \\
\hline Handicapped & 0 & 0 & 1 & 1 & \\
\hline \multicolumn{6}{|l|}{ 4-Education: } \\
\hline Illiterate & 0 & 1 & 3 & 4 & \multirow[t]{2}{*}{0.324} \\
\hline Read, write & 31 & 17 & 19 & 68 & \\
\hline Diploma & 10 & 7 & 3 & 20 & \multirow[t]{2}{*}{$\mathrm{P}<0.01$} \\
\hline Above average & 4 & 3 & 1 & 8 & \\
\hline University & 0 & 0 & 0 & 0 & \\
\hline
\end{tabular}

Concerning the relationship between the quality of life and some demographic variables. Table (5) revealed a statistical inverse correlation of the quality of life in menopausal women with their age $(\mathrm{P}<0.01$ and $\mathrm{r}=$ $-0.310)$. Also the same table showed that the quality of life in menopausal women varied according to their marital and occupational status $(\mathrm{P}<0.01)$. It also showed that the quality of life in menopausal women had statistically significant correlation with their educational level $(\mathrm{P}<0.01$ and $\mathrm{r}=0.324$ ).

Table(6): Correlation between the quality of life of the studied women and their level of chronic disease. ( $n=100)$.

\begin{tabular}{|c|c|c|c|c|c|}
\hline \multirow[b]{2}{*}{ Level of chronic disease } & \multicolumn{4}{|c|}{ Quality of life } & \multirow[b]{2}{*}{$\mathrm{r}$-Test } \\
\hline & $\begin{array}{l}\text { Average } \\
\mathrm{N}=45\end{array}$ & Poor $\mathrm{N}=29$ & $\begin{array}{l}\text { Very } \\
\text { Poor } \\
\mathrm{N}=26\end{array}$ & $\begin{array}{l}\text { Total } \\
\text { No }\end{array}$ & \\
\hline Mild & 19 & 6 & 6 & 31 & 0.104 \\
\hline Moderate & 25 & 14 & 9 & 48 & $p<0.001$ \\
\hline Severe & 1 & 9 & 11 & 21 & \\
\hline
\end{tabular}

Table (6 ) reveals that there was a positive association between severity of chronic disease and lower level of QOL during the menopausal period. 
Minia Scientific Nursing Journal (Print) (ISSN 2537-012X) Vol. (3) No. (1) July 2018

Table(7): Correlation between the quality of life of the studied women and their level of menopausal symptoms. (n=100).

\begin{tabular}{|c|c|c|c|c|c|}
\hline \multirow[b]{2}{*}{ Level of menopausal symptoms } & \multicolumn{4}{|c|}{ Quality of life } & \multirow[b]{2}{*}{$\mathrm{r}$-Test } \\
\hline & $\begin{array}{l}\text { Average } \\
\mathrm{N}=45\end{array}$ & Poor $\mathrm{N}=29$ & $\begin{array}{l}\text { Very } \\
\text { Poor } \\
\mathrm{N}=26\end{array}$ & $\begin{array}{l}\text { Total } \\
\text { No }\end{array}$ & \\
\hline Mild & 34 & 14 & 2 & 50 & 0.863 \\
\hline Moderate & 10 & 13 & 18 & 41 & $\mathrm{p}<0.001$ \\
\hline Severe & 1 & 2 & 6 & 9 & \\
\hline
\end{tabular}

Table (7 ) clarifies that there was a strong association between severity of menopausal symptoms as "vasomotor, somatic, , psychosomatic, urogenital symptoms" and lower level of QOL during the menopausal period.

Table(8): Correlation between the quality of life of the studied women and their level of body activities. (n=100).

\begin{tabular}{|c|c|c|c|c|c|}
\hline \multirow[b]{2}{*}{ Level of body activities } & \multicolumn{4}{|c|}{ Quality of life } & \multirow[b]{2}{*}{$\mathrm{r}$-Test } \\
\hline & $\begin{array}{l}\text { Average } \\
\mathrm{N}=45\end{array}$ & Poor $\mathrm{N}=29$ & $\begin{array}{l}\text { Very } \\
\text { Poor } \\
\mathrm{N}=26\end{array}$ & $\begin{array}{l}\text { Total } \\
\text { No }\end{array}$ & \\
\hline Mild & 31 & 15 & 22 & 68 & 0.821 \\
\hline Moderate & 9 & 12 & 3 & 24 & $\mathrm{p}<0.001$ \\
\hline High & 5 & 2 & 1 & 8 & \\
\hline
\end{tabular}

Table (8) illustrates that there was a positive association between decrease in the level of body activities with their Low level of QOL

\section{Discussion}

In the current century, population aging phenomenon occurred due to a decrease in mortality rate, advances in medical sciences, health education and increase in life expectancy. Although women and men have common health issues, women face specific issues arising from their physiological conditions. One of these issues is menopause transition period that is associated with complications.( 16)

The present study sample was Quasi- experimental , which aims to evaluate self care guideline on the menopausal related symptoms and their impact on the women's quality of life and assess factors that affect QOL as physical, psychological, motor, and sexual. Twice through pretest and posttest after using guide line .The study was implemented in Obstetrics and Gynecology department at maternity and children's hospital in Elmina city (hospital of obstetrics \&gynecology and children is this university hospital on a total of 100 woman complaining of with menopausal symptoms.

The current study revealed that the age of women ranged from 45-65 years with a mean age of 53.6 \pm 5.3 years. Similarly , a study done by Gehad M, Samia A and Galila S(17) indicated menopause was $46.35+4.8$ years in Egypt and mean age in Saudi Arabia was $49 . \overline{9}+\ldots 2.23$. so the present study fall between the normal ranges of menopausal age.

The current study found that the highest mean score was related to women's Mobility(2.22 \pm 0.9 ), as compared with the lowest mean score were related to women (Psychological 1.65 \pm 0.91 , Physical $1.49 \pm 1.0$, and Sexual $1.49 \pm 1.0$ respectively. This mean that the most common symptoms that sever hot flushes and sweating were presented in more than half $(56 \% \& 52 \%)$ of menopausal women This may correlates with decrease levels of estrogen in the blood from premenopausal to postmenopausal period . These results agreed with Greenblum (18) who indicated that the most commonly experienced symptom was hot flashes, with $73.2 \%$ of women currently experiencing that symptom.

Similarly, the previous studies stated that Menopause symptoms are closely related to QOL of women during menopausal period and can influence QOL of women both physiologically, psychologically, and socially. Some other Studies in Iran and other countries suggested negative effect of menopause on QOL in menopausal women.( 19)

The current study reveals a positive association between severity of chronic disease and lower level of QOL during the menopausal period. Shyu et al reported that the presence of menopausal symptoms increases the likelihood of poor health-related QOL and health care resource utilization. (20)

The current study assessed the association between some socio-demographic characteristics and QOL. For instance, age, level of education and marital status were found to be associated with QOL.

The current study revealed a statistical inverse correlation of the quality of life in menopausal women with their age it also presented some resistance for improving the quality of life due to an increase of the age of the woman. But the quality of life gradually improved after using guide line similarly, a study by Norozi et al(21) investigated the relation between many demographic factors and severity of 
QOL and concluded that age, marital status, employment status, and education levels affected the QOL in postmenopausal women.

The studies showed that demographic characteristics and menopausal symptoms experienced by women influenced their QOL in menopausal period. With increased life expectancy and life time, the QOL became an important issue. (22)

The results of the current study indicate that married women had a better QOL than widows. The marital status is considered one of the most important reinforcing factors that help women bypass the negative impacts of menopause, depending on the social support provided by the spouse. This study showed the positive impact of having a husband on mitigating the symptomatology of menopause. These results agreed with The study by Alipur et al., who investigated the role of social support in the QOL of the elderly and showed that the QOL in men was higher than women, and social, emotional, functional, and structural support had an important role in improving QOL. The results of a study by Dickson et al, showed that self-care programs, exercise, and work increase the QOL. (23), (24)

The educational level also was a factor affecting the QOL in postmenopausal women because educated woman easily used guideline. This is on line with Aloumanis et (25) who stated high QOL and expressed that women with high education level had higher QOL compared with other women. Perhaps, having higher life facilities, higher awareness, and educational level were related to higher QOL in these women.

This agreed with the study done by Kalahroudi MA (26) who reported that menopausal symptoms had significant association with working status, educational level, exercise activity, exercise frequency and duration of menopause. Several studies have shown that women who had longer education, reported milder menopausal symptoms.

Most Indian women remain oblivious to menopausal problems due to lack of awareness and unavailability or ever-increasing cost of the medical and social support systems (27). However, some recent studies on this subcontinent showed that working status, higher economic condition, higher educational attainment, occupational status of spouse and urban living may develop a positive attitude towards menopause and improve menopause-specific quality of life of middle-aged women (28)

Promoting the health and providing wellbeing in women's life period bring about better QOL of them and it will have useful outcomes for the society. In recent years, medical professionals have been focusing on training and informing programs for improving health status in women. (29)

The present study also highlighted the positive impact of interventional programs, as enabling factors, on the QOL of menopausal women. In general, women who had greater access to enabling factors also had a better QOL. One of the enabling factors in this study was the participation in the educational program on the issues of menopause. Various studies show that participation in such programs, in addition to increasing the awareness of women, improves their attitude, and they feel more confident, powerful, and valuable. Therefore, they feel menopausal $P$ a g e $\mid 41$ symptoms with less intensity and their quality of life improves.( 30)

In the field of educational programs as an important enabling factor in improving the QOL in postmenopausal women.

In accordance, Fishback,. (31) conducted an interventional program on menopausal women in order to improve their QOL regarding their physical and psychological symptoms, and reached a conclusion that appropriate training of menopausal women can improve their QOL and promote their health.

The present study was also comparable with that of the study performed by Garcia and Gomez-Calcerrada (32) on Spanish postmenopausal women. They showed that implementation of a cognitive behavioral intervention based on healthy lifestyle education led to a reduction in menopausal symptoms, especially depression and anxiety, in the intervention group. In that study, healthy lifestyle education was held through eight sessions for the intervention group. After implementing the educational intervention, a significant reduction was observed in menopause symptoms in the intervention group compared to the control group that had not received any training.

Results of the current study were also consistent with those of the study conducted by Sehati (33) in Iran. That study demonstrated that implementing educational intervention based on lifestyle education was effective in increasing health promoting behaviors and improving menopause symptoms. In that study, the intervention group participated in three sessions for three consecutive weeks. Four weeks after the intervention, a statistically significant difference was observed in menopausal symptoms in the intervention group, while the changes in the control group were not significant.

Similarly, Anderson (34) carried out a research on Australian postmenopausal women and reported that a multifaceted intervention through implementation of a 12week educational program on healthy lifestyle was effective in increasing health-promoting behaviors and improving menopausal symptoms. In that study, the results of post-test showed a significant reduction in depression, anxiety, hot flushes, night sweats, and physical problems in the group that had received face-to-face education and counseling.

\section{Conclusion}

Based on the present study Quality of life in menopausal women was greatly enhanced after 24 weeks of using self-care guideline and also guideline is an effective complementary health approach for improving quality of life in menopausal women.

\section{Recommendation}

- $\quad$ Self-care guideline should be used in health care centers as a routine care for menopausal women.

- Further study is necessary to identify factors affecting QOL for menopausal women's symptoms.

Heba A., et al 


\section{References}

[1]. Hess R, Thurston RC, Hays RD, Chang CC, Dillon SN, Ness RB, et al.2012 The impact of menopause on health-related quality of life: results from the STRIDE longitudinal study. Qual Life Res 2012; 21: 535-44.

[2]. ABC of yoga.com.yoga for menopause.2014 Cope with menopause through yoga. [Accessed February 8, 2014]. Available from: www.staryoga.com/yoga-for-menopause

[3]. About.com. 2014Stress management in menopause. [Accessed March 6, 2014]. Available from: menopause.about.com/od/managing menopausal stress.

[4]. Menopause. National Institute on Aging. (2017) http://www.nia.nih.gov/health/publication/menopau se. Accessed April 24,

[5]. Parandavar, N., Mosalanejad, L., Ramezanli, S., \& Ghavi1, F. (2014). Menopause and Crisis? Fake or Real: Comprehensive Search to The Depth of Crisis Experienced: A Mixed-method Study. Global Journal of Health Science, 6(2), 246-255.

http://dx.doi.org/10.5539/gjhs.v6n2p246

[6]. Taylor, Carol R.; Lillis, Carol; LeMone, Priscilla; Lynn, Pamela (2011). Fundamentals of Nursing. Philadelphia: Wolters Kluwer Health. p. 74. ISBN 978-0-7817-9383-4.

[7]. Burgers JS, Grol R, Klazinga NS, Mäkelä M, Zaat J (2011). "Towards evidence-based clinical practice: an international survey of 18 clinical guideline programs". Int J Qual Health Care. 15: 31-45. doi:10.1093/intqhe/15.1.31

[8]. Yazdkhasti M, Keshavarz M, Merghati Khoei E, Hosseini AF.2012 The effect of structured educational program by support group on menopause women's quality of life. Iran J Med Edu . 11: 986-94.

[9]. Wikipedia: The Free Encyclopedia. (2010): Qol (health care), Available at http: // en. Wikipedia. Org/ wiki Qol (health care).

[10]. Park K. Park's2011 textbook of preventive and social medicine. New Delhi, ID: Bhanot Publishers

[11]. Cohen S, Rousseau M and Carey BL (2013) Can acupuncture ease the symptoms of menopause? Holistic Nurse Practitioner, 17(6), pp.295-299.

[12]. Ibrahim, Z. M., Ahmed, W. A. S., \& El-Hamid, S. A. (2015). Prevalence of menopausal related symptoms and their impact on quality of life among Egyptian women. Clinical and Experimental Obstetrics \& Gynecology, 2(1), 161-167.

[13]. AnnPietrangelo(2014)http://www.healthline.com/ health/menopause/fac ts-statisticsinfographic\#1
[14]. American College of Obstetricians and Gynecologists(2011) Midlife Transitions: Perimenopause to Menopause. Accessed August 07, 2011

[15]. McKinney ES, Ashwill JW,(2012) Murray SS,James SR, Gorrie TM, Droske SC.MaternalChild Nursing. St. Louis:Elsevier Science Health Science Division.

[16]. Monshipour SM, Mokhtari-Lakeh N, Rafat F, Kazemnejad- Leili E. (2016) Related factors to menopausal women's quality of life in Rasht. J Holist Nurs Midwifery; 26: 80-8.

[17]. Gehad M, Samia A and Galila S. ., 2010 Effect of Menopausal Symptoms on Women's Quality of Life in Benha City (Egypt) and Arar City (Kingdom of Saudi Arabia). Med. J. Cairo Univ, 78 (1): 319- 330

[18]. Greenblum, CA., Meredeth A. Rowe, NeffDF., and Greenblum, GS 2012., Midlife women: symptoms associated with menopausal transition and early post menopause and quality of life. Journal of the North American Menopause Society, , 20, 1.

[19]. Abdi N, Solhi M.( 2014) Quality of life in postmenopausal women in Tehran. Iran J Health Educ Health Promot; 2: 87- 96.

[20]. Shyu YK, Pan CH, Liu WM, Hsueh JY, Hsu CS, Tsai PS. (2012) Health-related quality of life and healthcare resource utilization in Taiwanese women with menopausal symptoms: a nation-wide survey. J Nurs Res.;20:208-218

[21]. Norozi E, Mostafavi F, Hasanzadeh A, Moodi M, Sharifirad G. (2011) Factors affecting quality of life in postmenopausal women, Isfahan,. J Edu Health Promot 2013;2:58

[22]. Barati M, Ahmadpanah M, Shirahmadi S, Bashirian S, Parsa P, Holsboer-Trachsler E, et al(2016). Differential impact of sociodemographic variables on the quality of life of menopausal Iranian women. Avicenna J Neuro Psych Physiol; 3: e39026

[23]. Alipur F, Sajjadi H, Foruzan A, Biglarian A. (2010)Role of social quiet on elder's quality of life. Soc Welfare Quart.;4:147-165

[24]. Dickson VV, Howe A, Deal J, McCarthy MM.(2012) The relationship of work, self-care, and quality of life in a sample of older working adults with cardiovascular disease. Heart Lung;41:5-14

[25]. Aloumanis K, Karras D, Drossinos V, Korelis E, Polydorakis A. (2011)Fracture incidence, quality of life, and back pain during 18-months treatment with teriparatide in Greek postmenopausal women with osteoporosis: Results from the European Forsteo Observational Study. J Osteoporos 2011: 510398. 
[26]. KalahroudiM A., Mahboubeh T., Sadat z.,Saberi F3, and Karimian 2012 Z., Prevalence and Severity of Menopausal Symptoms and Related Factors Among Women 40-60Years in Kashan, Iran, Nurse Midwifery Stud.: 1 (2); 88-93. DOI: $10.5812 / \mathrm{nms} .8358$

[27]. Ray S .(2010) Is menopause a health risk for Bengali women? OpenAnthropol J 2010 ; 3 : 161 7.

[28]. Dasgupta D , Ray S .(2013) Attitude toward menopause and aging: astudy on postmenopausal women of West Bengal . J Women

[29]. Stanhope M, Lancaster J(2015). Public health nursing. 9th ed. St. Louis, MO: Mosby.

[30]. Nadrian H, Morowati Sharifabad MA, Soleimani Salehabadi H. 2010 Paradims of rheumatoid arthritis patients quality of life predictors based on path analysis of the Precede model. J Hormozgan Univ Med Sci.;14:32-44
[31]. Fishback, Alexa. (2010). Women's Health Daily Fix: Handbook of Healthy Habits for the Nutrition Savy Working Girl

[32]. Garcia CL, Gómez-Calcerrada SG. (2011)Cognitive-Behavioral Intervention among Women with Slight Menopausal Symptoms: A Pilot Study. The Spanish Journal of Psychology, 14(1), 344-355.

[33]. Sehhati F, Mirgha M, Jafari M. (2014) Effect of Education through Support Group on Early Symptoms of Menopause: A Randomized Controlled Trial. Journal of Caring Sciences; 3(4), 247-256

[34]. Anderson, D., Seib, C., McGuire, A., \& PorterSteele, J. (2015). Decreasing menopausal symptoms in women undertaking a web-based multi-modal lifestyle intervention: The Women's Wellness Program. Maturitas, 81، 69-75. http://dx.doi.org/10.1016/j.maturitas.2015.02.263 